\title{
DOR-DESPRAZER-TRABALHO DOCENTE: COMO DESFAZER ESSA TRÍADE?'
}

\author{
Maria Elizabeth Barros de Barros ${ }^{2}$ \\ Ana Paula Louzada ${ }^{3}$
}

Resumo: $\mathrm{O}$ artigo apresenta a experiência do Programa de Formação e Investigação Sobre a Saúde e o Trabalho (PFST) de docentes de escolas públicas, desenvolvido na Universidade Federal do Espírito Santo. Trata da problemática da saúde do conjunto de docentes que trabalham nas escolas públicas do município da Serra/ES, visando a desfazer a tríade dor-desprazer-trabalho docente, vivida de forma naturalizada pelo coletivo de docentes. Pretende avançar na compreensão das relações saúde-trabalho nas escolas e investigar as estratégias utilizadas por esses professores para resistirem às tentativas de desqualificação do trabaIho docente. Afirma a possibilidade de se abrirem espaços de discussão no cotidiano dos docentes para que a luta pela saúde se constitua em redes de cooperação entre sujeitos e escolas, inaugurando-se outras formas de atuação desses estabelecimentos. Com esse objetivo, propõe uma metodologia de trabalho que tem se pautado na abordagem ergológica, construída na Universidade de Provença, em AIX/ França.

Palavras-chave: Trabalho docente. Saúde do trabalhador. Ergologia.

\section{Introdução}

A pesquisa-intervenção que passamos a relatar faz parte do Programa de Formação e Investigação sobre a Saúde e o Trabalho (PFIST) de docentes das esco-

1 Este debate foi desenvolvido por Barros e Barros (2007).

2 Professora do Departamento de Psicologia e do Programa de Pós-graduação em Educação da Universidade Federal do Espírito Santo. E-mail: betebarros@uol.com.br.

3 Doutoranda do Programa de Pós-graduação em Educação da Universidade Federal do Espírito Santo. Professora da Faculdade Salesiana de Vitória. E-mail: paula-louzada@ig.com.br. 
las públicas e é uma continuidade das investigações que o Núcleo de Estudos e Pesquisas de Subjetividades e Políticas (Nepesp), do Departamento de Psicologia e do Programa de Pós-graduação em Educação da UFES, vem realizando desde 1998, operando na rede municipal de educação dos municípios da Grande Vitória.

O Nepesp trata da problemática da saúde, em suas múltiplas dimensões, do conjunto de docentes que trabalham nas escolas públicas do município, visando, como anuncia o título do artigo, a desfazer a tríade dor-desprazer-trabalho docente, vivida de forma naturalizada pelo coletivo de docentes com que tem trabalhado nos últimos anos.

Para esta investigação, o PFIST formou 22 trabalhadores, que deveriam fazer pesquisas sobre seus locais de trabalho e instituir Observatórios de Saúde e Trabalho nas escolas de ensino fundamental da Serra, município da Grande Vitória, no Espírito Santo. Focalizamos a situação desses trabalhadores sobre o pressuposto de que a forma como se organiza o trabalho na escola tem efeitos na saúde/doença dos docentes, e procuramos avançar na compreensão dessas relações articulando dados e reflexões de que já dispúnhamos aos que colhemos e analisados neste estudo.

Baseados em outras pesquisas do Nepesp (Barros, 1997, 2000), consideramos fundamental investigar as estratégias desses trabalhadores para resistir às tentativas de desqualificação do trabalho docente. Nessa perspectiva, não entendemos que as lutas e batalhas cotidianas produzam o adoecer, mas, pelo contrário, devem ser uma possibilidade de escapar à servidão, à obediência e à impotência, criando outras possibilidades de vida/trabalho.

Assim, urge que se repensem as diretrizes que devem nortear os processos de trabalho/saúde na educação brasileira, para adotar e subsidiar a construção permanente de relações e ambientes de trabalho saudáveis nas escolas. As pesquisas sobre a saúde do trabalhador docente são ainda muito escassas no Brasil e a maior parte tem foco na doença, $\mathrm{e}$ não na produção de saúde.

Como tantos outros, e escola é um espaço formado por uma diversidade de relações e de criações que indica um funcionamento híbrido. Assim, as novas estratégias precisam ser conhecidas pelo coletivo, para transformarem a atual organização do trabalho. Acreditamos que é possível abrir espaços de discussão no cotidiano dos docentes para que a luta pela saúde se constitua em redes de cooperação entre sujeitos e escolas e para se inaugurarem outras formas de atuação desses estabelecimentos. Para tanto, as invenções que os trabalhadores já produzem em seu cotidiano devem ganhar visibilidade, para potencializar formas coletivas de expansão ilimitada da vida e da saúde.

Para analisar o trabalho como espaço de negociações cotidianas que disparam estratégias híbridas, propomos uma metodologia que tem 
se pautado na abordagem ergológica, construída há 20 anos na Universidade de Provença, em AIX, na França. Originalmente, essa experiência veio atender a uma inquietação de profissionais que vivenciavam mudanças no mundo do trabalho e não sabiam como responder a essas questões ou enfrentá-las. Essa situação suscitou a criação de um dispositivo diversificado de aprendizagem recíproca entre as fontes de saber universitário requeridas para os empregos e ofícios e os novos saberes requeridos pelas novas configurações da atividade. Trata-se de um dispositivo pluridisciplinar e pluriprofissional, que visa a dar conta da complexidade do mundo do trabalho e de suas inúmeras atividades interrogando os saberes e todas as experiências industriosas envolvidas nesse processo.

Assim, em 1998, criou-se o Departamento de Ergologia da Universidade de Provença, em AIX, para promover a interlocução entre os diferentes saberes que sustentam atividades e experiências diversas. $\mathrm{O}$ objetivo da abordagem ergológica é criar estratégias e técnicas que viabilizem essa interlocução entre as experiências dos mundos do trabalho e os saberes das ciências.

É nesse contexto que elaboramos a presente pesquisa-intervenção sobre as condições de trabalho nas escolas do município da Serra, visando a articular pesquisa e programa de formação na direção apontada pela ergologia, ou seja, ampliar o diálogo entre os diferentes saberes, formando professores capazes de enfrentar as novas situações de trabalho da contemporaneidade.

O quadro teórico de que derivamos as questões para esta discussão é, na verdade, a explicitação do modo como entendemos estar colocada hoje a questão do trabalho nas escolas e os efeitos produzidos nos indissociáveis planos político e subjetivo. Com esse objetivo, as referências conceituais e metodológicas oferecidas pela Ergologia, dentre outras, sustentaram nossas investigações.

Nosso ponto de vista é, portanto, em certa medida, produzido no diálogo com interlocutores que partilham uma perspectiva ético-política do trabalho, numa perspectiva que concorra para a transformação da sociedade, no sentido"emancipador dessa transformação" (Zarifian, 1995). O movimento do real é indicador dessa transformação e de modalidades de relações que não só prefiguram, mas configuram uma sociedade alternativa. Segundo Zarifian (1995),

Não se trata de pensar uma sociedade futura, sob o modo de utopia, nem mesmo da revolta, mas de pensar o que é a sociedade na sociedade, o que é não da ordem do futuro, mas da construção. Trata-se de levar a sério a idéia de Marx, segundo a qual a transformação social reside no movimento do real. (p. 58)

O que nos interessa é conhecer mais de perto o que é vivido nas situações de trabalho hoje, diante das novas configurações do capitalis- 
mo, e avaliar que modalidades de relações existentes lhes fazem frente, mesmo que timidamente, ou seja, que indicam outros possíveis ${ }^{4}$. Existe um mundo a ser conhecido nos ambientes de trabalho - um mundo de problemas, de conceitos e de tentativas práticas, e é isso o que priorizamos. Portanto, o que é fundamental nessa estratégia de pesquisa é criarem-se esses possíveis, acreditando que vem deles grande parte do sofrimento, como do potencial de revolta contra o que está instituído e a criação de outras formas de trabalhar. Esse potencial existe e ele constitui o real, está no saber da experiência, "não é uma invenção de pesquisador otimista" (Zarifian, 1995, p. 59).

Consideramos que é necessário e urgente criar estratégias metodológicas que dêem conta da especificidade desse objeto de investigação que são as questões dos mundos do trabalho, uma vez que as limitações do conhecimento científico sobre essa temática só podem ser superadas se partirem dos "desafios e das indagações advindas da experiência daqueles que vivem as relações que investigamos" (Athayde, Brito, \& Neves, 2003, p. 240).

Portanto, nossa pesquisa-intervenção sustenta-se na indissociabilidade entre o docente como pesquisador, como participante ativo da gestão do seu trabalho e como conhecedor das dores e prazeres de seu fazer; conseqüentemente, o docente é capaz de produzir conhecimento acerca desse fazer e, ao mesmo tempo, produzir estratégias de visibilidade para os enfrentamentos e as resistências cotidianamente tecidas.Compartilhando as experiências individuais, é possível coletivizar estratégias e saberes. Por exemplo, durante uma oficina de trabalho, uma professora-pesquisadora conta que andava lentamente até a sala, como forma de instaurar um intervalo que não existe mas que é imprescindível para continuar o trabalho. Entre sorrisos e falas, o grupo de professores se identificou com esse andar lento e, assim, pôde-se perceber o quanto aquele andar, de alguma forma, é coletivo e gestor de trabalho-saúde.

Esta pesquisa foi desenvolvida para entender esses "andares" e neles intervir, salientando seus traçados impregnados de sentidos.

Problematização: o cotidiano como lugar de análises

Como se movimentam os docentes no trabalho em sala de aula, na sala dos professores, com seus pontos diários, nos corredores povoados de afetos e sinetas? Que jogos acionam? Que engrenagens põem em funcionamento? Como se gerem entre formas panópticas, corporificadas

4 É importante destacar que, quando usamos a expressão "possíveis", não estamos nos referindo a possibilidades, ou seja, à disponibilidade atual de um projeto por realizar ou "a série de alternativas reais e imaginárias (ou...ou...), é preciso entendê-la como emergência dinâmica de novo" (Zourabichvili, 2000, p. 337). Não se tem o possível antes de tê-lo criado. Assim, o campo dos possíveis não se confunde com a delimitação do realizável num determinado momento. 
pelas divisões espaciais e temporais, pela vigilância dos alunos e das coordenações pedagógicas e, insidiosamente, pela autovigilância? Como lidam com seus fazeres transformados em números, feito posições numa escala? Como tecem no cotidiano outros usos não previstos? Como circulam pelos movediços da fragmentação de seus fazeres? De que maneiras enfrentam a solidão de suas práticas? Que alianças tecem? Que nomes assinam? Que recusas estabelecem, em meio a um trabalho que toma a vida em toda a sua extensão?

Que dramáticas dos usos de si vivenciam? Que distâncias experimentam entre o trabalho prescrito e o trabalho real?

De que formas agenciam produções de sentidos em suas atividades? Como tecem, lidam com o caráter extenuante e, ao mesmo tempo, empobrecido de suas tarefas? Como os docentes agem a partir da prescrição no seu trabalho? Como, ao trabalhar, inventam mundos, se constituem?

Foram essas questões que conduziram esta pesquisa na UFES e, como ferramenta para a análise do trabalho docente, abordamos prioritariamente seu fazer cotidiano. Mas será o cotidiano um campo válido de estudo? Como e por que estudá-lo? Que concepções estão em jogo, para afirmá-lo como um lugar de fazeres e saberes que se podem apreender?

O cotidiano inventa muitas maneiras não autorizadas ou antevistas, como peças de um quebra-cabeça por criar. No cotidiano, fabricam-se outras maneiras de usar os objetos, possibilitando metamorfoses inúmeras e infinitesimais. Assim, para analisar o cotidiano, é preciso inventar outros instrumentos, que não aqueles preditos pela racionalidade científica - há que mergulhar no interjogo, apontando a marginalidade das reinvenções trilhadas silenciosamente.

Como caçadores, restam aos indivíduos astúcias, reinvenções dos códigos demarcados. Dessa forma, ler, conversar, habitar, cozinhar - fazeres e sabores cotidianos - permitem jogar com os acontecimentos, sem nomeá-los, datá-los ou produzir lugares. Fazeres que, por seus usos, (re)introduzem mobilidades de interesses e prazeres.

Os modos de vida prescritos recusam essas mobilidades exatamente por não serem cognoscíveis ou dignas de se tornar cognoscíveis, já que, há quatro séculos, aprendemos a desqualificar os saberes cotidianos, pois resultavam de senso comum, que precisava minimamente do filtro da ciência para ser confiável (Garcia \& Alves, 2002).

Mas como reconhecer as multiplicidades desses conhecimentos, se os produzimos em nossas ações cotidianas? Sua análise não se torna irremediavelmente comprometida, já que, para compreender, é preciso separar sujeitos e objetos? Ora, com outras lógicas - como notam Garcia e Alves (2002), é urgente narrar a vida. 
É imprescindível tomar os fazeres cotidianos como espaços de gestão e afirmação da vida. Logo, analisar o trabalho docente necessariamente como cotidiano é enfocar seus contornos, suas nuances e suas trilhas silenciosas. Trata-se de dar visibilidade a táticas que resistem à captura da lógica que busca sobrecodificar a vida, modelando-a a partir de metro padrão.

As texturas cotidianas são tecidas pela e na História. Abordar o campo do trabalho docente exige analisar os processos constitutivos das formas pelas quais ele passa a ser pensado/exercido como um objeto natural, como superfície de normatização social e também como as mutações na produção e o lugar ocupado interferem diretamente no mecanismo de controle sobre os corpos.

Nesse percurso, Foucault (1998) é um grande aliado, pois propõe uma análise insidiosa, uma pesquisa dos detalhes que passa ao largo das grandes categorias, das produções reconhecidas. Para ele, "a história não tem 'sentido', isso não quer dizer que seja absurda ou incoerente. Ao contrário, é inteligível e deve poder ser analisada em seus menores detalhes, mas segundo a inteligibilidade das lutas, das estratégias e das táticas" (p. 5).

Para talhar essa inteligibilidade das lutas, das estratégias e das táticas, Foucault (1998, p. 14) aborda os mecanismos de poder como produtores de verdades, entendidas como um "conjunto de procedimentos regulados para a produção, a lei, a repartição, a circulação e o funcionamento de enunciados".Trata-se, pois, de restituir à História todos os acontecimentos, principalmente aqueles tidos como isentos dela, por cortes genealógicos:

A genealogia não pretende recuar no tempo para restabelecer uma grande continuidade para além da dispersão, do esquecimento; sua tarefa não é mostrar que o passado ainda está lá, bem vivo no presente, animando-o ainda em segredo, depois de ter imposto a todos os obstáculos do percurso uma forma delineada desde o início. Nada que se assemelhasse à evolução da espécie, ao destino de um povo. Seguir o filão complexo da conveniência é, ao contrário, manter o que se passou na dispersão que lhe é própria: é demarcar os acidentes, os ínfimos desvios - ou, ao contrário, as inversões completas -, os erros, as falhas na apreciação, os maus cálculos que deram nascimento ao que existe e tem valor para nós; é descobrir que não há raiz daquilo que somos - não existe a verdade e o ser, mas a exterioridade do acidente. (p. 21)

Se nossas formas constituídas de vida são exterioridades de acidentes marcadas por lutas, e não evoluções, se aquilo que acreditamos serem modos universais de mundos são mecanismos engendrados em contextos ao mesmo tempo específicos e dispersos, então, restam-nos não a dúvida do cogito cartesiano, mas as análises micropolíticas dos mecanismos de poder instalados nas produções de verdades. 
A proposta foucaultiana radicaliza as noções de naturalidade do estar no mundo. Frases como "o trabalho tudo vence,"'mente vazia, oficina do diabo" ou "o trabalho enobrece o homem" traduzem imperativos tidos como universais, solidamente firmados desde os primórdios da humanidade. Mas trabalhar não faz parte de uma suposta essência humana - nada é a priori ou natural nesse campo, mas há produções, engendramentos e enunciados que foram tornados imperativos.

Segundo Foucault (1998), os sujeitos humanos se constituem numa negociação permanente com um código moral definido por um conjunto de "aparelhos prescritivos" que diz da forma como entram nos jogos de verdade, numa prática de autoformação que não é exclusivamente coercitiva. Como uma dessas máquinas prescritivas, a escola se constitui como um conjunto de valores e regras propostos como ação para os indivíduos. A esse processo, Foucault (2004) nomeou:

(...) "prática ascética”, dando a asceticismo um sentido muito geral, ou seja, não o sentido de uma moral da renúncia, mas o de um exercício de si sobre si mesmo através do qual procura se elaborar, se transformar e atingir um certo modo de ser (p. 265)

A discussão proposta aqui aborda a forma como cada docente vive esse código, seu comportamento em relação a essas regras, a maneira como se submete a esses princípios de conduta, obedecendo/resistindo à interdições/prescrições, pois as regras não estão só explicitadas e formuladas em doutrinas coerentes e em ensinamentos explícitos, mas também são transmitidas "de maneira difusa e se constituem num jogo complexo de elementos que se corrigem, se compensam e se anulam em alguns pontos, permitindo compromissos ou/e escapatórias" (Foucault, 1998, p. 18).

Entendemos, assim, que a maneira pela qual o professor se deve constituir a si mesmo como sujeito no trabalho docente tem como referência de ação os elementos prescritivos que constituem o código. Mas há diferentes maneiras de se conduzir frente a um código - diferentes maneiras de o educador/docente agir como sujeito moral dessa ação. Estamos falando de modos de sujeição aos códigos prescritivos, à maneira pela qual o indivíduo estabelece sua relação com essa regra e se reconhece ligado à obrigação de pô-la em prática. Trata-se, no sentido foucaultiano, de um trabalho ético sobre si mesmo, não só para conformar seu próprio comportamento a uma regra dada, mas também para tentar transformar a si mesmo em sujeito moral de sua conduta.

A constituição dos sujeitos de ações, por meio de "práticas de si",é que vai constituir modos de subjetivação e de subjetividade que constituem esse trabalhador da educação. Assim, para entender as diferentes formas de uso que põem em funcionamento, é preciso considerar a 
indissociabilidade dos códigos de comportamento prescritos e as formas de subjetivação em curso nas escolas.

Interessa-nos o modo como os professores trabalham, para além da execução das tarefas prescritas nas escolas, engendrando tentativas de se fazerem sujeitos de sua ação. Assim, é preciso indagar: que práticas de si estão se operando nas situações de trabalho nas escolas? Como esses trabalhadores "des-anonimam" seu ambiente de trabalho? Essas são as questões que priorizamos aqui, tendo como conceitos/ferramentas a intercessão das formulações foucaultianas na abordagem ergológica de Yves Schwartz, o que não significa identificá-las, mas tomar-lhes emprestado o que puder contribuir para a construção do caminho metodológico/ analítico. Esses intercessores podem desestabilizar o processo da pesquisa e produzir movimentos importantes para sua efetivação, ou seja, ferramentas-intercessoras que estabelecem uma relação de perturbação criadora, cruzamento que desestabiliza e faz diferir.

\section{De que trabalho docente falamos? Trabalho como usos de si}

Nossas análises perspectivam seguir os "fios" do trabalho real e os "usos de si por si e pelos outros" colocados em ato nas escolas. Diríamos, com Schwartz (1992), que o "uso de si por si traz a marca do que é para o homem a herança da vida dele" (p. 19). Trata-se de uma retroação do humano sobre o ser vivo, a partir de uma concepção mesma da vida que os estudos sobre a atividade no trabalho nos conduzem a considerar:

As modalidades de uso de si remetem certamente também aos destinos individuais, às negociações, por sua vez particulares, entre a cena coletiva e o que a história produziu em cada um de nós como marcas "particulares". Do ser vivo ao ponto de vista privado, permanece-se no individual, do ser vivo aos atos de trabalho, permanece-se na dinâmica da atividade, do trabalho ao privado, na história e no simbolismo. (p. 20)

Seguindo as formulações de Canguilhem (2000), Schwartz (1992) afirma que "essa enigmática continuidade do vivente ao humano industrioso como fabricação de microdescontinuidades, de irrever-sibilidades"é o que denomina "recentramento" parcial em torno de entidades humanas que estão mais ou menos circunscritas. Somos aqui levados a perguntar, com Schwartz (1992): "não seria exatamente esse 'fato biológico', esse incessante debate do vivente com seu meio a própria'condição de possibilidade' de toda história?" (p. 109).

No curso dos processos de trabalho, os "viventes humanos industriosos" (Schwartz, 1992) travam uma luta cotidiana por modos de viver que afirmem a vida como tendência criadora. Os movimentos dessa natureza que estão acontecendo nas escolas são muitas vezes insuficientes para 
sustentar essa ontologia criacionista que é o projeto dos vivos. Portanto, podemos estar cegos, surdos e insensíveis a essa luta em curso, porque há circunstâncias em que elas se dão de forma camuflada. Assim, como projeto de nossas ações nesse âmbito, esse modo de problematizar as situações do trabalho docente implica o acompanhamento desses movimentos que vão se desenhando nos estabelecimentos educacionais, instituindo contornos, recortando, isolando e elegendo o que produzem/ reproduzem e só então a detecção dessas lutas, dando-lhes visibilidade.

Nesse sentido, a Ergologia é um potente intercessor que, ao se apropriar de conceitos de diferentes disciplinas, aponta as (re)singularizações parciais inerentes às atividades de trabalho para esse fazer industrioso que é o fazer humano. Para Schwartz (2002), "o que importa à Ergologia no campo das atividades humanas é sempre, num certo grau, história" (p. 135). O trabalho é um lugar de problematizações, ou seja, um lugar que convoca os sujeitos a fazerem escolhas no sentido de se darem novas normas, tornando a vida possível de ser vivida no meio de trabalho.

Na perspectiva de Canguilhem (2000), o que caracteriza o vivo é exatamente essa capacidade de ser normativo, ou seja, essa possibilidade que a vida encontra de instituir normas em condições diferentes dos espaços existenciais, o que significa poder acompanhar as transformações que a vida está sempre a produzir. Entendemos, assim, que o meio social humano se caracteriza pela "fragilidade" - é um mundo em que os acidentes ocorrem, desafiando a capacidade humana de intervir, de propor soluções para os problemas apresentados. Nesse regime de funcionamento, o meio em que vivemos não impõe soluções determinadas, mas pede uma ação que pode adquirir nuances variadas, a partir da experiência de cada sujeito, para o enfrentamento de um mesmo problema. Essa capacidade avaliativa se expressa na medida em que os trabalhadores estão constantemente repensando e construindo formas de tornar suas tarefas menos maçantes. $O$ trabalho demanda arbitragens, engajamentos, escolhas e reajustes para os imprevistos. Nisso reside a infidelidade do meio, pois os acontecimentos são as transformações processando a história no mundo.

A imprevisibilidade do real e a variabilidade das situações de trabalho que as pessoas encontram a cada dia envolvem diferentes processos decisórios que apontam a gestão micropolítica no exercício da atividade. Desse modo, entendemos que, embora sob condições muito adversas, quando a máquina do trabalho busca engolir os atos criadores, os ambientes laborais também se constituem "espaço de possíveis" em que os sujeitos se manifestam no ato de trabalho por meio da "atividade industriosa" (Schwartz, 2002) e pela diversidade de "usos de si" que sinalizam a afirmação do movimento da vida.

Assim, trabalhar inclui necessariamente a possibilidade de se introduzirem mudanças na realização da tarefa, múltiplas formas de criação e 
de iniciativas, o que distingue o trabalho prescrito, entendido como espaço em que pessoas vivenciam escolhas entre as formas cristalizadas de trabalho historicamente construídas e o trabalho real, que é o trabalho concreto, com suas imprevisíveis variações.

A atividade em situação de trabalho está em constante movimento, e a cada dia "coisas novas" se apresentam, suscitando nos sujeitos a realização e o prazer, vivido inclusive no corpo, quando este sinaliza a ausência do cansaço. Aqui se opera com a concepção do trabalho como "usos", na medida em que a relação homem/trabalho é sempre um "encontro histórico" em que se confrontam os saberes científicos consolidados e os saberes da prática - ou essa construção industriosa (Schwartz, 1992) -, permitindo o caminhar da História humana. Nesse "encontro" (Schwartz, 2002), em que há sempre um destino a ser vivido, há uma"dramática" em que os sujeitos têm que fazer escolhas, arbitrar entre valores diferentes, muitas vezes contraditórios, uma situação em que cada um deve gerir sua atividade de um modo ou de outro. Isso quer dizer que não existe situação de trabalho que não convoque "dramáticas do uso de si", quando "cada um avalia a trajetória e o produto, ao mesmo tempo individual e social, do que é levado a fazer" (Schwartz, 1998, p. 107).

Assim, encontramos ressonância nos trabalhos de Foucault (1998), quando nos fala sobre as práticas de si, uma vez que os sujeitos se constituem na negociação permanente com um código moral definido pelos "aparelhos prescritivos" como a família e a igreja e também as instituições educativas. Como vimos, a máquina prescritiva escola se constitui ao mesmo tempo como um conjunto de valores prescritos e regras propostas como ação para os indivíduos e grupos. No entanto, cada indivíduo - seu comportamento real em relação a essas regras - vive esse código de maneira singular, obedecendo ou resistindo a uma interdição ou prescrição.

Precisamos do prescrito, pois a organização é necessária a toda atividade humana, mas não precisamos nos engessar no que está prescrito a ponto de impedir ou perturbar a própria realização do trabalho. O educador nunca é um mero executor do prescrito, mas antes um agente singularizador do coletivo. Trata-se, então, de uma liberação do trabalho docente, que não se reduz a uma reação ao que está instituído, já que as práticas de liberdade estão no plano do instituinte, de criação (Foucault, 2004). Não basta romper "com esses ferrolhos repressivos para que o homem se reconcilie consigo mesmo, reencontre sua natureza ou retome contato com sua origem e restaure uma relação plena e positiva consigo mesmo" (Foucault, 2004, p. 265).

O autor nos alerta de que, para que se efetivem as práticas de liberdade, é necessário o cuidado de si, que visa ao bem dos outros e a administrar o espaço de poder presente em qualquer relação, o que significa administrar os espaços no sentido da não dominação. Assim, o cuidado 
de si é prática de liberdade, uma ética que usa o prescrito de forma inventiva, não permitindo que as prescrições formatem o real a partir de um metro padrão, numa atividade de trabalho que é uma atitude de vida, em que o cuidado de si não se separa do cuidado com o outro. Esse aspecto está muito presente no trabalho educacional. Como indica Maia (2006):

Cuidado de si que se desdobra naquela abertura à diferença, necessária à relação intercessora, através do qual esse "si" não pode ser um dentro impermeável ao fora, mas um dentro-fora ao mesmo tempo, de tal forma que só pode transitar através de uma fronteira nômade, sempre em movimento. (p. 164)

Então, a prática da liberdade ética no campo da educação - liberdade como condição ontológica da ética (Foucault, 2004) - não se efetiva devido a alguma ordem transcendente, mas pelo fato de que, ao desenvolver suas atividades, o docente opera desvios criadores, num engajamento que vai produzindo fissuras na rede pública de educação, uma linha de fuga para um cuidado intercessor que se institui nas ações potentes e éticas dos profissionais da educação.

O cuidado com o aluno é necessariamente um cuidado de si, que encontra tempo para o corpo do aluno, que não se deixa aprisionar pelo aparelho prescritivo escola, que se cria e recria no concreto da experiência, sem se deixar cristalizar por um ideal educacional marcado pela falta, por um espaço constituído pela dominação e por uma vida despotencializada pela abstração.

Schwartz (2003) chamou "dramáticas de si" essas escolhas que são feitas quase inconscientemente:

(...) uma vez que não somos obrigados a nos perguntar sem cessar "o que estou fazendo, como escolho etc." ou a tentar decompor, desdobrar essas múltiplas arbitragens que se situam no corpo, entendido não como o que se opõe à alma, mas como um corpo atravessado pela inteligência e também por automatismos que podem vir à consciência. (p. 13)

Portanto, o autor prefere denominar "corpo si" essas microcriações, porque são sempre atravessadas por uma inteligência que marca essas escolhas diante da atividade e nem sempre são conscientes. Essa inteligência do corpo atravessa os músculos, os líquidos, os nervos, a postura e o imaginário, mas não se restringe ao biológico ou ao cultural, antes perpassando todos esses circuitos. O "corpo si" é algo que escapa às cristalizações e que remete à história, à experiência, às paixões e aos desejos dos sujeitos que trabalham para dar continuidade ao movimento da vida. 
Perseguindo os caminhos indicados pelas ferramentas conceituais e metodológicas escolhidas, abordamos os sentimentos que o trabalho provoca e mobiliza - as "dramáticas do uso de si"- de forma a viabilizar uma análise coletiva do trabalho e a criação de outros modos de se operar o trabalho docente.

Como estratégia metodológica, utilizou-se a Comunidade Ampliada de Pesquisa (CAP) que visa a articular os saberes que construímos na academia com os saberes dos próprios trabalhadores-docentes, para que, juntos, pudéssemos produzir novos modos de gestão do trabalho na escola que possibilitassem a potencialização e a manutenção de espaços de análise e discussão coletiva, levando a intervenções tanto no ambiente quanto no próprio modo de se ser educador (formação de um trabaIhador/pesquisador). Assim,"a esse novo tipo de relação, de encontro, de diálogo crítico entre o pólo dos saberes presentes nas disciplinas científicas e o pólo dos saberes colocados em prática e desenvolvidos no cotidiano de trabalho, batizamos aqui de Comunidade Ampliada de Pesquisa CAP" (Athayde et al., 2003, pp. 13-14).

O método consiste na criação de grupos de trabalhadores-docentes que deviam explicar aos pesquisadores sua atividade, isto é, o que fazem no seu trabalho pedagógico, segundo as seguintes etapas:

\section{Etapa 1:}

a) contato com o sindicato dos trabalhadores em educação do Estado do Espírito Santo e com a Secretaria de Educação do município da Serra, para divulgação da pesquisa;

b) reunião com os professores que participaram das outras pesquisas realizadas no Nepesp (Barros, 1997, 2000), para que, juntos, pesquisadores da UFES e professores multiplicadores pudessem construir os passos da pesquisa a partir dos dados obtidos nos trabalhos anteriores.

\section{Etapa 2:}

a) oficinas de produção de conhecimento e discussão dos temas relacionados com o trabalho docente: saúde, trabalho/gestão, etnia, gênero e readaptação. Cada um desses temas se constituiu num módulo do processo de formação e se efetivava em dois fins de semana, tendo sido coordenados por um grupo de especialistas nesses temas participantes da pesquisa; 
b) metodologia de cada módulo: o desenvolvimento de cada módulo foi construído pelos coordenadores, de modo que, no primeiro momento, os professores recebiam material bibliográfico sobre o tema em foco e, no final do dia, orientações para atividades que deveriam ser realizadas no intervalo dos encontros e apresentadas no segundo dia de trabalho. Ao final de cada módulo, os professores avaliavam o processo vivido e se faziam as articulações necessárias para o módulo seguinte.

\section{Etapa 3:}

a) alternância entre dois momentos: primeiro, o retorno dos trabaIhadores a seus locais de trabalho para exercícios de "estudo de campo"; segundo, encontros mensais para discussão da experiência, dos achados e das possíveis mudanças já realizadas com a CAP após cada exercício. Os estudos de campo visavam a um mapeamento das condições de trabalho nas escolas, realizado pelos professores a partir das ferramentas teórico-metodológicas adquiridas nos módulos temáticos. Assim, ao final da etapa 2 , os trabalhadores escolheram um foco de pesquisa para ser explorado nos estudos de campo com os outros colegas das escolas. Para cada grupo de trabalhadores/docentes em campo, constituiu-se uma equipe de pesquisadores do projeto que acompanhou o estudo, auxiliando-os. Como estratégias de pesquisa nos ambientes de trabalho, os professores usaram observações do cotidiano, entrevistas, leituras de documentos relativos ao tema da pesquisa, diário de observações de campo e grupos focais, entre outros;

b) restituição das análises e discussão dos estudos feitos com a CAP: mensalmente, após os estudos de campo, os educadores/docentes retornavam aos encontros com a CAP, para levar subsídios para uma análise coletiva das situações de trabalho e então construir estratégias coletivas de monitoramento das condições de saúde e da organização do trabalho nas escolas.

O foco de pesquisa para o estudo de campo foi: sinais de adoecimento e formas de enfrentamento. Com essa perspectiva, definiuse que deveriam ser analisados:

a) aparecimento e repercussões - para si, para os outros e para o trabalho - desses sinais;

b) diferentes formas de encaminhamento utilizadas - licença, readaptação e outros "jeitinhos" etc.;

c) diferentes formas de enfrentamento dos processos de adoecimento em curso ou de seus sinais. 
Para os estudos de campo dos docentes nas escolas onde trabalhavam, definiram-se as seguintes estratégias:

a) entrevistas individuais com os outros colegas da escola;

b) grupos focais: dois encontros, no mínimo, para os grupos de docentes formados em cada escola, com duração média de 30 minutos;

c) questionários aplicados a todos os professores da escola onde trabalhavam;

d) observação participante do cotidiano das escolas: cartografia e diário de bordo.

Tanto para as entrevistas individuais quanto para os questionários e os grupos focais, definiu-se um Roteiro a ser seguido: escola?

a) Você(s) sabe $(m)$ ou conhece $(m)$ algum sinal de adoecimento na

b) Quais são as repercussões desses adoecimentos para a escola, para cada um de vocês e para o trabalho na escola?

c) Vocês têm sentido algum problema relativo à saúde? Quais seriam?

d) Que situações, na escola, teriam desencadeado esses adoecimentos?

e) Como estamos encaminhando essa situação? Que formas utilizamos para encaminhar esses adoecimentos na escola?

f) Como lidamos com os problemas que trazem adoecimento e ainda continuamos trabalhando?

g) Vocês podem apresentar sugestões para mudar situações que produzem adoecimento?

Como estratégia para facilitar o estudo de campo, o grupo decidiu usar as reuniões para a construção do projeto político-pedagógico das unidades escolares, com calendário já definido nas escolas, para fazer os grupos focais, as entrevistas ou a aplicação de questionários. Escolheuse também uma comissão, constituída por professores e alguns pesquisadores do Nepesp, para negociar com a Secretaria e a direção das esco- 
las e garantir os espaços para a realização dos trabalhos da pesquisa com os professores interessados em participar.

Concluída essa etapa, cada professor apresentou um relatório com uma exposição detalhada do movimento dos grupos focais, indicando o número de encontros, a duração e quantos professores participaram, bem como uma descrição dos resultados obtidos e das dificuldades encontradas.

\section{Desdobramentos do processo de pesquisa/formação}

Após a experiência vivida no PFIST, foi possível dar visibilidade à situação dos professores nas escolas, mas sobretudo afirmar o protagonismo dos docentes na tarefa de se desfazer a tríade dordesprazer-trabalho docente.

Os relatos dos docentes que nos chegaram, a partir das situações vividas durante o PFIST, apontaram insistentemente essa relação dordesprazer-trabalho docente, colocada em análise durante o processo de pesquisa, que mostrou a precarização das relações de trabalho nas escolas, pelas formas instáveis de contratação (como a designação temporária - DT), pelo baixo investimento em formação e pelos fracos vínculos que os trabalhadores estabelecem nos e com os seus espaços/processos de trabalho.

Essa situação desemboca muitas vezes na busca de "tratamentos", ou soluções que ora se voltam para o trabalhador em sua situação individual de adoecimento, ora se convertem em reivindicações, cada vez mais fragilmente organizadas e orientadas para o conjunto de trabalhadores (Barros \& Barros, 2007). Durante a pesquisa, não era nossa meta deixar de valorizar as várias ações dirigidas à escuta e a encaminhamentos nesses âmbitos, mas nos chamou atenção a sistemática (re)incidência das queixas e do modo como elas eram respondidas - na maioria das vezes, como ressentimento ou falta -, com frágeis propostas de formulação de políticas para transformar a situação vivida.

Segundo os docentes:

A categoria tem vários problemas como: desunião, baixa auto-estima, inveja e principalmente o individualismo. O professor que faz o trabalho com carinho não é bem recebido.

Há uma forte hierarquia na escola: não é escravidão, mas a coisa não é bonita.

Há professoras que não querem mais nada, não se empenham mais.

Eu caí na pressão do dia-a-dia da escola e tive que recorrer a um psiquiatra.

O problema é que não há união na escola. 
Quinze anos de profissão e ouço sempre a mesma fala [...] e isso afeta a criança. Tentei fazer um trabalho com os pais, mas chamaram minha atenção.

Acho que precisamos de socorro.

Há falta de educação por parte dos professores. Na hora das reuniões, o olhar deles diz o seguinte: 'Meu corpo está aqui, mas minha mente....'Mas, apesar disso, eu insisto. Apesar de ouvir falas como 'Ah, isso é utopia', tenho buscado fazer encontros na escola para discutir nossa situação.

Após a pesquisa, alguns docentes observaram mudanças no comportamento de alguns colegas:

Havia uma questão quanto à amabilidade, porque, antes, eu não recebia nem sorrisos, havia certo armamento. Agora, tem aumentado o grau de amor, mas ainda há separação. Não é que existissem só coisas ruins, mas melhorou depois da CAP.

O curso (PFIST) contribui para vencer a resistência de muitos colegas.

Conseguimos nos reunir com a diretora, apesar das dificuldades.

Acho que, apesar dessas dificuldades, está para florescer alguma coisa.

Em algumas escolas, foram instituídos encontros mensais e reuniões de estudo com multiplicadores (docentes que participaram do PFIST), professores regentes e o CTA, com duração de duas horas e meia. Esses encontros de atividades presenciais foram coordenados pelas multiplicadoras-professoras participantes da CAP.

Outros professores elaboraram uma tabela com as causas de estresse nas unidades educacionais e a indicação de sugestões para minimizá-las. Numa das escolas, elaborou-se um projeto de estudo, que se encaminhou à Secretaria Municipal de Educação (SEDU) para implantação na rede educacional, que inclui o debate sobre saúde/doença dos docentes. Os docentes também fizeram atas de reuniões e documentos decorrentes do projeto e estudo com os temas do curso - saúde, gênero, etnia, readaptação e trabalho - para apresentação e debate com os colegas da escola, assim como avaliação e certificação para todos os participantes do processo na escola.

Coube aos participantes da CAP, multiplicadores do processo de formação nas escolas, contribuir para o cumprimento da pauta e enriquecer os debates com questionamentos pertinentes, concorrendo para a mudança de postura dos docentes no que tange à relação saúde/doença nas escolas.

Destaque-se que os multiplicadores-docentes integrantes da CAP custearam as despesas do estudo de campo realizado nas escolas: cópias do Caderno de Textos e do Caderno de Métodos e Procedimentos utili- 
zados no PFIST e dos trabalhos enviados à Anped para serem apresentados na categoria pôster.

Uma professora apresentou o seguinte argumento:

Tivemos a oportunidade de elaborar e encaminhar um projeto de estudo para a SEDU Serra, bem como executá-lo e, com isso, exercitamos a elaboração de registros, vivenciamos as dificuldades para cumprir o cronograma e dar continuidade às discussões, o que foi viabilizado pelo processo de formação experimentado no PFIST no que diz respeito à saúde do trabalhador em educação.

A partir dos dados obtidos nos debates com a CAP e dos resultados dos estudos de campo, o grupo de pesquisadores da UFES e os docentes do município da Serra definiram alguns desdobramentos que serão pactuados com a SEDU:

a) negociar com a Secretaria de Educação para que cada escola tenha um dia livre para realizar as atividades da pesquisa sobre as articulações saúde-trabalho nas escolas;

b) montar um curso de gestão participativa para o coletivo de trabalhadores de educação da Serra;

c) promover uma reunião semestral da CAP, para manter o debate sobre a situação analisada, e fazer os encaminhamentos necessários para a efetivação do que foi acordado ao longo da pesquisa;

d) inserir o tema "Saúde no trabalho" no planejamento das escolas;

e) fazer uma síntese do tema do curso com definições e perguntas;

f) criar um observatório da saúde na escola.

g) fazer um levantamento dos pedidos de licenças médicas para a Secretaria de Educação; escolas;

h) montar um curso sobre Gestão Colegiada para os diretores das

i) constituir um grupo de trabalho da Secretaria de Educação para multiplicar o PFIST na rede de ensino da Serra;

j) instituir um Núcleo de Saúde do Trabalhador Docente na SEDU. 
A CAP possibilitou o entrelaçamento de questões teóricas, efetivamente vividas em suas dimensões muitas vezes conflitantes de dor e prazer. Uma pergunta insistia: se o trabalho é adoecedor e exaustivo, por que o professor volta ao trabalho? Que dimensão é essa que move o desejo de persistir? Instigados por essa pergunta, alguns professores respondiam imediatamente que era em nome da sobrevivência, mas outros afirmavam que era pelo fato de continuarem se inquietando, se surpreendendo nos encontros com os alunos, pelo fato de o trabalho produzir sentidos para além das pautas, chamadas, indisciplinas, três turnos da jornada diária e problemas nas cordas vocais.

Um professor, em particular, apontava sempre o quanto é prazeroso inventar um jeito novo de fazer o mesmo, pois, dizia ele, "o conteúdo é o mesmo, mas eu e os alunos somos outros, né?".

\section{Conclusões}

Essa pesquisa, realizada em conjunto com os docentes do município da Serra, se constituiu num espaço rico de trocas e análises efetivas das atividades em curso no cotidiano das escolas e apontou o trabalho como algo além do desgaste e do adoecimento, possibilitando apreender sua dimensão inventiva.

Como a metodologia de trabalho implicava a constante análise dos discursos sobre o trabalho vivo, os professores eram instigados, pelo grupo de pesquisadores da UFES e também pelos outros professores, a confrontar suas falas com as estratégias naturalizadas de culpabilização individual como, por exemplo, aquele professor não se compromete, ele 'enrola', pede licença médica, porque não dá conta de trabalho pesado.

$\mathrm{E}$, como multiplicadores, muitas vezes após realizar os encontros nas escolas, os professores percebiam a reprodução desses discursos culpabilizantes e o quanto esses discursos engessam as formas de enfretamento no campo estritamente individual: Se eu adoeço por não agüentar o barulho infernal da escola, que está funcionando num lugar provisório, e tiro licença, sou visto como um 'enrolador' [não seria 'enrola a dor'?], deixando uma turma sem aula, aumentando o barulho na escola.

Desfazer a tríade dor-desprazer-trabalho no cotidiano escolar exige dar visibilidade a práticas gestadas nos momentos de execução, no trabalho em ato.

Se adoecer não é meramente individual, mas decorre da forma de viver a organização prescritiva do trabalho que atravessa o coletivo - um dos indícios desse adoecimento nos professores do município da Serra pode ser percebido pelo alto número de licenças médicas, de causas variadas -, a produção da saúde também não é de uma esfera só individual. Certamente, a saúde, assim como o adoecimento, acometem sujeitos in- 
dividuais, encarnados, mas os processos de saúde são necessariamente disparados pelos/nos coletivos.

O trabalho na escola é espaço de atividade (Schwartz, 2002) que ultrapassa as tarefas realizadas no dia-a-dia, como uma faculdade do ser vivo de inventar normas de trabalho que afirmem o processo vital. Então, falamos de uma abordagem do trabalho docente que tenta encontrar, em cada circunstância, um núcleo de renormalização, o que significa que cada um de nós, no cotidiano do trabalho, pode se descobrir a si mesmo e aos outros não como meros executantes de uma instrução ou de um procedimento (a submissão total às normas), mas antes como atores/autores de uma realização parcialmente original, de uma renormalização (atualização das normas por alguma pessoa).

Apreender e aprender essa inventividade, a potencialização do corpo, dos saberes e dos fazeres marca o professor para além das marcas tão conhecidas e relatadas pela literatura e incorporadas pelos corredores, intervalos e olhares da escola: de impotência, desgaste e submissão.

As excessivas prescrições e cobranças produzidas no espaço escolar podem minimizar a capacidade normativa dos próprios trabalhadores, mas essas prescrições - com seu conteúdo prévio e seu planejamento - acerca do trabalho do professor nunca são seguidas de forma absoluta.

Por mais que o corpo seja marcado pelo uso que o outro faz do trabalhador (o regulamento da escola, a carga horária, o conteúdo a ser ministrado), há uma dimensão microgestionária das dramáticas de uso de si em que "o trabalho nunca é expectativa do mesmo e repetição - mesmo que o seja, em parte" (Schwartz, 2003, p.4).Por mais minuciosas que sejam as normas do trabalho prescrito, alguma coisa sempre escapa.

Assim, durante a pesquisa-intervenção, interessava-nos essa dimensão da produção de subjetividade em curso nos processos de trabalho nas escolas, pois é importante que as práticas educativas possam afirmar a dimensão do afeto e se redirecionar no sentido do encontro entre corpos vivos - alunos, equipe técnica, professores -, sem deixar de considerar a vida em seu movimento. Impõe-se hoje o (re)ordenamento de uma razão técnica, que muitas vezes se apresenta como estratégia para construir uma outra/nova forma de educação considerada "em crise", de modo a não enquadrar o vivo nessa racionalidade e perder de vista esse movimento da vida, deixando escoar por entre nossos dedos essa potência inventiva em curso nas escolas.

É preciso aguçar as lentes para enxergar a teimosia, as apostas individuais e coletivas dos professores. Queremos amplificar os sons, conhecer os ruídos e silêncios, quer sejam gritos ou sussurros, para que nos ajudem a também mapear os sinais de luta contínua pela vida e a acompanhar os movimentos instituintes no trabalho dos educadores/docentes (Barros, Marchiori, \& Oliveira, 2005). 
Aumentar o grau de autonomia dos trabalhadores nos processos de pensar-fazer seu trabalho e a abertura dos processos de criação, sustentando a indissociabilidade entre práticas educacionais e gestão, permite, a nosso ver, "transitar da dor ao prazer no trabalho, sem que com isso caiamos na banalização do sofrimento ou na idealização do prazer" (Barros \& Barros, 2007, p. 15).

Foi o que buscamos com o desenvolvimento desta pesquisa.

\section{Pain-displeasure-teachin work: how to undo this triad?}

Abstract: This paper presents an experience of the Investigation and Formation Program on Health and Work of public school teachers, developed at the Federal University of Espírito Santo. It brings into question the health of all the teachers who work in public schools in Serra, a city in the State of Espírito Santo, aiming to undo the triad "pain-displeasure-teaching work" experienced by the teaching-body. This work intends to advance the comprehension of the health-work relations at schools, and it also intends to investigate the strategies used by these workers when resisting the attempts to disqualify teaching work. It states the possibility of opening spaces for discussion in the daily lives of teachers so that the struggle for health becomes a cooperative net between subjects and schools in order to inaugurate other forms of performance in those establishments. Thus, this paper proposes a methodology of work which has been based on the ergologic approach, built at Provence University in AIX/France.

Keywords: Teaching work. Occupational health. Ergology.

\section{Douleur-soufrance-travail des enseignants: Comment defaire cette triade?}

Résumé: Cet article présente l'expérience du Programme de Formation et Investigation Recherche sur la Santé et le Travail des enseignants des écoles publiques soutenu à I'Universidade Federal do Espírito Santo. Il s'agit d'un abordage thématique de la santé des professeurs qui travaillent à la ville de Serra, Espírito Santo, sous régime municipal. On a le but de défaire la triade établie chez ces prefessionnels: douleur - soufrance - travail. On a donc le but d'avancer dans la compréhension du rapport santé-travail dans les écoles en examinant les stratégies qui font de la résistence face aux tentatives de décalification du travail des professeurs. II nous semble qu iil est possible d'entretenir un débat quotidien sur leur métier en constituant un réseau de coopération propice a des nouvelles formulations et aussi a des nouvelles pratiques. La méthodologie utilisée dans cette recherche est celle proposée par l'ergologie, créé à l'Université d'Aix-en-Provence.

Mots-clés: Travail des enseignants. Santé et travaille. Ergologie. 


\section{Dolor-desplacer-trabajo docente: ¿Cómo deshacer esa tríada?}

Resumen: Este artículo presenta la experiencia del Programa de Formación e Investigación sobre Salud y Trabajo (PFST) de docentes de escuelas públicas, que se ha desarrollado en la Universidad Federal de Espírito Santo. Discurre sobre la problemática de la salud de los docentes que trabajan en las escuelas públicas del municipio de Serra/ES, pretendiendo deshacer la tríada: dolor-desplacertrabajo docente, vivida de modo naturalizado por el colectivo de docentes. Pretende avanzar en la comprensión de las relaciones entre salud-trabajo en las escuelas e investigar las estrategias utilizadas por dichos trabajadores en el sentido de resistir a las tentativas de descalificación del trabajo docente. Afirma la posibilidad de que se abran espacios de discusión en el cotidiano de los docentes para que la lucha por salud se haga en redes de cooperación entre sujetos y escuelas, encaminándose hacia la inauguración de otras formas de actuación en tales establecimientos. Con ese objetivo, propone una metodología de trabajo basada en la aportación ergológica que se construyó en la Universidad de Provenza, en AIX/ Francia.

Palabras-clave: Trabajo docente. Salud laboral. Ergología.

\section{Referências}

Athayde, M., Brito, J. \& Neves, M. Y. (Orgs.). (2003). Caderno de textos: programa de formação em saúde, gênero e trabalho nas escolas. João Pessoa: Universitária.

Barros, M.E.B. (1997). Relatório de pesquisa. Departamento de Psicologia, Ufes.

Barros, M.E. B. (2000). Relatório de pesquisa. Departamento de Psicologia, Ufes.

Barros, M. E. B., \& Barros, R. B. (2007). Da dor ao prazer no trabalho. In S. E. Santos \& M. E. B. Barros (Orgs.), Trabalhador da saúde: muito prazer! Protagonismo dos trabalhadores na gestão do trabalho em saúde (pp. 61-72). Ijuí, RS: Unijuí.

Barros, M.E.B.,Marchiori,F.,\& Oliveira,S.P.(2005).Atividade de trabalho e saúde dos professores: o programa de formação como estratégia de intervenção nas escolas. Revista Trabalho, Educação e Saúde, 3(1), 143-170.

Canguilhem, G. (2000). O normal e o patológico (5a ed.). Rio de Janeiro: Forense Universitária.

Foucault, M. (1998). Microfísica do poder. Rio de Janeiro: Graal.

Foucault, M. (2004). A ética do cuidado de si como prática de liberdade. In M. Foucault, Ética, sexualidade, política (pp. 264-287). Rio de Janeiro: Forense Universitária. 
Garcia, R. L., \& Alves, N. (2002). A necessidade da orientação coletiva nos estudos sobre coletivo: duas experiências. In L. Bianchettil \& A. M. N. Machado, A bússola do escrever (pp. 23-36). São Paulo: Cortez.

Maia, M. A. B. (2006). O corpo invisível do trabalho: cartografia dos processos de trabalho em saúde. Dissertação de Mestrado, Universidade Federal Fluminense, Niterói, RJ.

Schwartz, Y. (1992). Travail et philosophie: convocations mutuelles. Toulose: Octares.

Schwartz, Y. (1998). Os ingredientes da competência: um exercício necessário para uma questão insolúvel. Revista Educação e Sociedade, 65, 101-139.

Schwartz, Y. (2002). Disciplina epistêmica, disciplina ergológica: paidéia e politeira. Proposições, 13(37), 126-149.

Schwartz, Y. (2003). A abordagem ergológica do trabalho e sua contribuição para a pesquisa em administração. Trabalho apresentado no Seminário Internacional de Administração, Vitória.

Zarifian, P. (1995). Travial, événement et rapports sociaux. Le travail el l'événement. Paris: L'Harmattan.

Zourabichvili, F. (2000). Deleuze e o possível. In É. Alliez (Org.), Gilles Deleuze: uma vida filosófica (pp. 54-76). São Paulo: Editora 34.

Recebido em: 19/06/2007

Aceito em: 24/09/2007 